\title{
TRANSAÇÃO ADMINISTRATIVA: ENFRENTANDO O ARGUMENTO DA SUPREMACIA DO INTERESSE PÚBLICO
}

\author{
João Lucas Arcanjo Carneiro* \\ Rafael da Nobrega Alves Praxedes**
}

\section{RESUMO:}

O caráter de supremacia prima facie do interesse público frequentemente dificulta a solução satisfatória de conflitos administrativos. Este artigo pretende sugerir que, sem desconsiderar o interesse público, seja superada, em alguma medida, a resistência da Administração Pública ao encontro de saídas mais práticas e efetivas às demandas envolvendo particulares, o que ocorreria por meio do instrumento da transação administrativa. Propõe-se, portanto, com base em metodologia de exploração bibliográfica e com propósito descritivo e exploratório, que, para haver efetividade na solução de demandas administrativas - sem que menospreze a coisa pública -, deve-se institucionalizar, no ordenamento jurídico, a transação administrativa.

Palavras-chave: Direito Administrativo. Supremacia do interesse público. Solução de litígios. Transação administrativa.

\section{ADMINISTRATIVE CLOSING AGREEMENT: FACING THE ARGUMENT OF THE SUPREMACY OF THE PUBLIC INTEREST}

\begin{abstract}
:
The feature of prima facie supremacy of the public interest often hampers the satisfactory resolution of administrative conflicts. This article argues that, without disregarding the public interest, it must be overcome the resistance of the Public Administration of finding more practical and effective remedies to demands involving citizens through the instrument of the administrative closing agreement. Therefore, it is proposed, using a methodology of bibliographic exploration, with descriptive and exploratory purpose, that, in order to be effective in the solution of administrative demands - without detracting from the public interest -, it is necessary to institutionalize the administrative closing agreement.
\end{abstract}

Key-words: Administrative Law. Supremacy of the public interest. Conflict resolution. Administrative closing agreement.

\section{INTRODUÇÃO}

\footnotetext{
* Procurador da Junta Comercial do Estado do Ceará. Especialista em Direito Previdenciário. Aluno do Mestrado em Direito ao Processo e ao Desenvolvimento do Centro Universitário Christus (UNICHRISTUS). E-mail: joaolucasarcanjo@gmail.com

** Mestrando em Direito e Desenvolvimento (UNICHRISTUS), Pós-graduado lato sensu em Direito e Processo do Trabalho. Advogado. E-mail: rafaelpraxedesadv@gmail.com
} 
No Brasil, a transação é uma forma de solução de litígio para demandas civis e tributárias. É um instrumento de negociação que envolve concessões mútuas entre os participantes de um acordo. Na Administração Pública de modo geral, entretanto, a transação ainda tem tímida presença, embarreirada pelo argumento da supremacia do interesse público sobre o individual, que tornaria indisponível a priori o objeto a ser transacionado somente pelo uso de tal justificativa.

Neste trabalho, será visto como a transação pode ser usada pelo Poder Público de forma útil e efetiva, como verdadeiro instrumento de defesa do interesse público em si, e não como ameaça. Será proposto, por fim, que se considere a elaboração de uma lei geral que trate da possibilidade da existência da transação administrativa, na qual o estabelecimento de condições para a negociação entre os litigantes fosse delegado diretamente ao Poder Público, uma vez que este tem mais conhecimento sobre o caso concreto e sobre os benefícios que uma solução rápida e sem eventual intromissão judicial traz à Administração Pública.

Por meio de análise bibliográfica e com utilização de método hipotético dedutivo, são debatidas, em um primeiro momento, questões concernentes ao interesse público (tópico 1). Em seguida, trata-se de como a transação é utilizada no ordenamento jurídico brasileiro para solução de demandas civis e tributárias (tópico 2). Adiante, pretende-se demonstrar que a transação administrativa tende a ser um instrumento de solução de conflitos envolvendo a Administração Pública, que não ofende o interesse público e traz efetividade e pacificação das demandas contra o Poder Público (tópico 3).

Sugere-se, por fim, que haja uma previsão legal de autorização direta para que a Administração Pública determine as condições da transação administrativa, modificando a situação atual, pela qual, pelo menos em matéria tributária, é necessária ordenação legal para cada caso em que se objetiva transacionar.

\section{ASPECTOS GERAIS RELATIVOS AO INTERESSE PÚBLICO}

O indivíduo é parte celular do organismo social que se organiza sob a presunção de soberania de suas ações um espaço físico que o engloba, possibilitando interações entre os indivíduos por meio de leis com presunção de acordo. Neste acordo implícito, cada indivíduo 
concede um pouco de si em favor da estabilidade do organismo, o qual, em contrapartida, garante a seus colaboradores bens, serviços e liberdades que o indivíduo por si teria dificuldades em conquistar ou sequer chegaria a ter possibilidade do usufruto. Em poucas palavras, o apresentado acima é, para o mais ou para o menos, um Estado ${ }^{1}$.

O Estado, como organismo que, grosso modo, serve para proteger suas partes, deve ter condições para essa função. Para tanto, também deve ter mecanismos que o protejam de danos indesejáveis, uma vez que indiretamente seriam danos destinados a cada componente do todo ${ }^{2}$. Sob esse argumento da proteção mediata do bem individual por meio da defesa imediata do bem coletivo, repousa quase que imperturbável ${ }^{3}$ o princípio da supremacia do interesse público, quando o coletivo, confrontado com o individual, teria presunção de predominância por um critério quase que objetivo de superioridade dogmática.

A necessidade de cooperação social também pode explicar a essencialidade do interesse público, oportunidade em que Holmes e Sunstein (1999, p. 220) comentam que os direitos dos cidadãos americanos (o que pode se estender a todas as nações democráticas):

Are neither divine gifts nor fruits of nature; they are not self-enforcing and cannot be reliably protected when government is insolvent or incapacitated; they need not be a recipe for irresponsible egoism; they do not imply that individuals can secure personal freedom without social cooperation; and they are not uncompromisable claims.

Para o interesse deste trabalho, que se centra na busca de uma possibilidade de transação útil e célere para os objetivos tanto da Administração Pública como do cidadão, deve-se, dessa forma, abordar inicialmente questões acerca do interesse público, que serve como proteção magnética a afastar eventuais soluções de desentrave de soluções perante o Poder Público, o que alimenta a litigiosidade desnecessariamente.

O princípio da supremacia do interesse público traz para si a indisponibilidade do interesse público, que seria justamente o entrave para o a melhora e liquidez das relações com o Poder Público. Embora usado como defesa da sociedade, contudo, o interesse público não

\footnotetext{
${ }^{1}$ COSKUN (2006, p. 593) trata do entendimento de Hobbes a respeito da interação entre a parte e o todo para a formação do Estado.

${ }^{2}$ KIRCHHOF (2016, p. 7) entende que "o patrimônio de qualquer um dos súditos compõe ao mesmo tempo uma parte do patrimônio total da república".

${ }^{3}$ BINENBOJM (2005. p. 9).
} 
pode servir para o bloqueio da utilização de certas liberdades - nem mesmo opor-se a soluções pragmáticas dentro da Administração Pública - apenas pela mera alegação de impossibilidade de atuação por causa de sua eventual indisponibilidade, como se tudo na esfera pública tivesse sido tocado por Midas (SCHIER, 2007, p. 163). Na verdade, como ainda indica Schier (2007, p. 169), “interesses públicos e privados se complementam e se harmonizam, não se encontrando, em regra, em conflito, pois a realização de um importa na do outro".

O interesse público, em que pese ter suas dificuldades de conceituação ${ }^{4}$ confundindo-se até com o serviço público ${ }^{5}$, pode tanto ser caracterizado como um fim ou como um processo. Naquela acepção, diz-se que, na Administração Pública:

O interesse público é o principal fim a ser atingido já que configurado, em termos, pela necessidade de carrear os recursos necessários ao próprio funcionamento do Estado, que infere diretamente na satisfação das necessidades da sociedade e na manutenção da ordem pública. Do mesmo modo, o agente da administração tributária não pode dispor dos bens, interesses e serviços públicos, uma vez que estes são indisponíveis por natureza (BOAROLI e PEIXOTO, 2011, pp. 225-226).

No que diz respeito à caracterização do interesse público como processo, Lewis (2006, p. 696) sustenta que "as a public service duty, the public interest is conceptualized more fruitfully as a process, not as an objectively identifiable endpoint. An elusive and sweeping obligation, it is a never-ending process that is made meaningful more by practice than by a product".

Por sua vez, Marins de Souza (2009, p. 57), argumentando quanto ao uso indiscriminado do princípio da supremacia do interesse público, diz que "trata-se de princípio não escrito, de conteúdo abstrato e incapaz de propor a subordinação pura e simples do interesse público sobre o privado".

\footnotetext{
${ }^{4}$ Houle e Mockle (1998, p. 742) relatam que: "Quant à la notion d'intérêt public, elle sert à interpréter la supranorme d'ordre public. Lorsqu'un juge est d'avis que le contrat intéresse l'ordre public, il doit examiner s'il s'agit d'une entente touchant l'ordre public de direction ou l'ordre public de protection. La distinction entre ces divisions de l'ordre public est souvent tenue".

${ }^{5}$ Simard (2005, p. 146) afirma que "il faut reconnaître que la difficulté persistante de définir des concepts $d^{\prime}$ ' intérét public » et de "service public » complique le présent exercice d'analyse. Leur interprétation varie d'une juridiction à l'autre et change au gré des époques et des contextes".
} 
Quanto à questão da indisponibilidade do interesse público, esse comando funciona, portanto, como uma indicativa de modus operandi solidificado para o administrador público, uma vez que partiria do pressuposto que demandaria "que os agentes estatais (mesmo de esfera federativa distinta) sejam diligentes em apurar e combater práticas atentatórias à moralidade e desviadas do bem comum" (LOPES FILHO, 2006, p. 332).

O princípio da supremacia do interesse público funciona, portanto, como um metaprincípio a ser observado tanto no processo de tomada de decisões como na finalidade do serviço público. Em que pese essa ostentação, a alegação de que o interesse público é indisponível tem sido utilizada em situações nas quais o uso poderia ser admitido. $\mathrm{Na}$ verdade, percebe-se que o interesse público pode ser utilizado de modo plenamente discricionário ou totalmente vinculado, a depender da vontade da Administração Pública. Nesse sentido, Gabardo (2017, pp. 99-100) indica que:

\begin{abstract}
O interesse público é um conceito que recebeu no decorrer da história significações que vão da absoluta discricionariedade à total vinculação. De qualquer modo é um conceito que foi e continuará a ser utilizado pelo Direito administrativo de forma ampla, ainda que diferente, em cada sistema jurídico concretamente considerado e em cada sociedade na qual inserido.
\end{abstract}

Ademais, ainda há quem defenda que a supremacia do interesse público não poderia ser considerada um princípio. Mais uma vez tomando por empréstimo as palavras de Gabardo, este, ao comentar o posicionamento de Humberto Ávila contrário à natureza de princípio que se objetiva dar à supremacia do interesse público, aduz que:

\footnotetext{
Ávila contesta tanto a possibilidade de que a supremacia seja um princípio quanto seja um postulado, em razão do que a distinção torna-se relevante apenas para melhor elucidar as conclusões de sua argumentação. $\mathrm{O}$ autor afirma que, da forma como considerada, a supremacia não seria um princípio na medida em que não admite ponderação nem concretização gradual; as suas possibilidades de concretização consistiriam em exceções e não graus, considerando que a prevalência é sua única possibilidade (GABARDO, 2017, p. 105).
}

Gustavo Binenbojm compartilha do sentimento original de Ávila. Para aquele, também não se admite a concessão de atribuição principiológica à supremacia do interesse público, isso porque, para o referido autor: 
Uma das categorias forjadas desde essa origem autoritária foi o chamado princípio da supremacia do interesse público sobre o interesse particular. Embora decantado pela literatura brasileira como fundamento e princípio normativo do direito administrativo, sua inconsistência teórica e sua incompatibilidade visceral com a sistemática constitucional dos direitos fundamentais são patentes. Com efeito, uma norma que preconiza a supremacia a priori de um valor, princípio ou direito sobre outros não pode ser qualificado como princípio (BINENBOJM, 2005, p. 29).

Tratado como princípio ou não, percebe-se que o interesse público deve ser levado em consideração nas atividades da Administração Pública, tendo em vista que, ao se fazer a escolha de proteção do coletivo, também se protege o individual, que se faz representar no todo.

No tópico a seguir, apresenta-se uma ferramenta que o Poder Público tem a seu dispor para, ainda com respeito à supremacia do interesse coletivo sobre o individual, dirimir as dificuldades para a solução de determinados casos envolvendo o patrimônio público, qual seja, a transação.

\section{TRANSAÇÃO NO ORDENAMENTO JURÍDICO BRASILEIRO}

Transação pode ter uma abordagem contratual-civil ou extintivo-tributária. O Código Civil, em sua parte especial, Livro I, Título VI, Capítulo XIX, onde se trata dos contratos em espécie - ou, de forma mais direta, art. 840 - dispõe que "é lícito aos interessados prevenirem ou terminarem o litígio mediante concessões mútuas".

O Código Tributário Nacional, por sua vez, em sua redação original, no art. 171, dispõe que "a lei pode facultar, nas condições que estabeleça, aos sujeitos ativo e passivo da obrigação tributária celebrar transação que, mediante concessões mútuas, importe em determinação ${ }^{6}$ de litígio e consequente extinção de crédito tributário". No parágrafo único do art. 171, ainda é estabelecido que "a lei indicará a autoridade competente para autorizar a transação em cada caso".

\footnotetext{
${ }^{6}$ Ou "terminação" - é o sentido que se dá a essa palavra para que mantenha a coerência com o objeto do dispositivo, qual seja, a transação.
} 
Percebe-se que o artigo que trata de transação no Código Tributário Nacional possui seu núcleo baseado no dispositivo do Código Civil, tendo em vista que ambos mencionam que a transação objetiva o término do litígio (ou terminação-extinção do crédito tributário) por meio de concessões mútuas ${ }^{7}$.

Há uma diferença mais substancial envolvendo os dois tipos de transação aqui citados. No Código Civil, a transação só é permitida para direitos patrimoniais de aspecto privado. Por outro lado, a transação tributária, por envolver o interesse público, trataria sobretudo de direitos de caráter público.

Sobre a transação no Direito Tributário, que não pode ser confundida com parcelamento, sugere-se que ela seria:

O acordo entre o Fisco e o sujeito passivo, dependente de lei autorizativa, com concessões mútuas. Assim, cada parte parcela de seu direito com o objetivo de atingirem ponto de interesse para ambas, terminando o litígio ou conflito de interesses e extinguindo o crédito tributário. A transação não se confunde com o parcelamento, pois a primeira é causa de extinção, enquanto que o segundo é causa de suspensão do crédito tributário (SARAIVA FILHO e GUIMARÃES, 2008, p. $18)$.

A transação tributária, que pressupõe a existência de litígio, não podendo ser utilizada para tratar da prevenção de litígio (SARAIVA FILHO e GUIMARÃES, 2008, p. 20), depende, portanto, de lei autorizativa. A lei irá mencionar as condições em que a transação poderá ser celebrada pela autoridade administrativa.

No tópico seguinte, faz-se proposta de alargamento do uso da transação tributária como mecanismo para a solução geral de conflitos da Administração Pública, por meio da adoção da transação administrativa. Oportunidade esta que tornaria prescindível lei autorizativa para todos os casos concretos, uma vez que o ordenamento deveria ser inovado com a previsão legislativa da possibilidade do uso da transação de forma direta pela Administração Pública.

\footnotetext{
${ }^{7}$ Tratando da transação no direito canadense, a transação também requer concessões mútuas: "Pour qu'il y ait transaction, il doit y avoir des concessions réciproques; les concessions unilatérales sont insuffisantes" (HOULE e MOCKLE, 1998, p. 738).
} 


\section{TRANSAÇÃO ADMINISTRATIVA E SEU SERVIÇO AO INTERESSE PÚBLICO}

Depois de ter visto separadamente as abordagens de interesse público e de transação, indaga-se: para tratar da possibilidade de uma transação facilitada, que não dependa apenas da permissão da lei para cada caso concreto ou que seja autorizada por um centro de competência restrito, de que forma o interesse público e a transação se relacionam? E até que ponto a alegação de defesa do interesse público pode ser substituída, no caso concreto, por decisões administrativas céleres e mais benéficas ao interesse público do que os eventuais prejuízos de litígios demorados, em que recursos ficam impedidos de ingresso no erário por eventual preciosismo legal? Ainda, quais benefícios a transação administrativa traria ao Poder Público e de que forma ela poderia ocorrer?

Para ajudar a entender essas questões, de início, é de bom modo entender que o interesse público alegado de forma difusa não pode servir como instrumento de defesa ou proibição da transação administrativa a todo e qualquer momento. Para tanto, Volpi (2011, p. 148) afirma que:

Cabe enfrentar a questão atinente à indisponibilidade do interesse público, caráter distintivo dos entes públicos que litigam, e que pode, à primeira vista, inviabilizar qualquer vislumbre de acordo ante a impossibilidade de tais entes transigirem com relação a seus interesses.

A transação pode ser encarada como uma negociação que, justificada diretamente no interesse público, pretende oferecer soluções efetivas para as questões que envolvem a Administração Pública e o particular. Nesse sentido, tratando da situação da renegociação dos contratos que envolvem o Poder Público, sob o prisma de que a Administração Pública tem como saber, no caso concreto, o que deve ser melhor para si, Schiefler (2016, p.3) argumenta que:

Em suma, são diversos os casos em que a negociação pode gerar soluções criativas que prestigiam os interesses públicos de maneira mais apurada que a simples aplicação das soluções já previstas na legislação. Retirar da Administração Pública a possibilidade de negociar soluções alternativas ao descumprimento contratual por parte do contratado significar privá-la da busca pela melhor forma de satisfazer seus 
próprios interesses, que, como se sabe, devem ser coincidentes com os interesses públicos.

Percebe-se que, a partir do momento em que se reconhece que a lei não tem habilidade de captar todas as situações sociais e prever condutas específicas para todo caso concreto, deve-se prover o administrador público de mais liberdade para atuar e para negociar. Negociação esta que deve também respeitar a integridade dos interesses coletivos, posto que colocados sob prevalência - embora não absoluta - sobre os particulares.

A negociação, por sua natureza conceitual, implicará em eventuais prejuízos para a Administração Pública, isso não se pode descartar. Até porque a transação é mecanismo que envolve concessões mútuas e, por conseguinte, pressupõe eventuais prejuízos. Entretanto, também haverá ganhos. E é quando a Administração Pública, por ato motivado, perceber que tende a garantir o interesse público de uma melhor forma por meio da transação no caso concreto, e não por meio do advento de uma lei autorizadora ou de inevitável arrastamento judicial, é que a transação administrativa deve ser utilizada e incentivada.

Nesse sentido, ao comparar transação a contratos, Terry (1973, p. 430), considerando que as partes devem decidir, de acordo com o caso concreto, se a transação atenderá aos interesses de ambos, indica que:

Closing agreements are a useful device for determining tax liabilities or for determining the tax treatment of specific items. As with a contract, only those matters that are specifically spelled out in the agreement will be considered as covered. An understanding of the legal consequences of a closing agreement obviously places one in a position to analyze whether a closing agreement is desirable.

Do excerto, infere-se o que já tem sido defendido: a transação administrativa é ferramenta a se colocar ao dispor do Poder Púbico para que a utilize quando entender e justificar o seu cabimento com base justamente no interesse público.

Mas como isso poderia ocorrer? É certo que, no momento, a transação especialmente a tributária - precisa ser autorizada por lei. Segundo o Código Tributário Nacional, em seu artigo 171, por meio da lei autorizativa, as condições da transação são estabelecidas. Dessa forma, a autoridade estaria vinculada a transacionar nos limites postos 
pela lei, não podendo aperfeiçoar e incrementar negociações, mesmo que seja mais benéfico ao Poder Público.

Tal circunstância pode ser observada, em paralelo, nas infrutíferas audiências de conciliação com participação da Fazenda Pública, cujos representantes se veem impossibilitados de firmarem acordos por falta de autorização específica. Ao tratar desse tema, Volpi identifica que há orientações Advocacia Geral da União (AGU) sobre como os advogados públicos devem proceder em determinadas matérias. No entanto, Volpi ainda não considera que exista a liberdade de atuação necessária para a atuação dos membros da AGU em audiências de conciliação para que possam acordar sobre um amplo leque de assuntos:

Em que pese a existência de tais regramentos, a disciplina ainda é muito tímida. Basta imaginar o número de ações em que são partes a União e outros entes federais. É inviável a autorização do Advogado-Geral da União e dos dirigentes dos entes federais em cada uma dessas causas. Como consequência disso, pouquíssimos acordos são firmados (VOLPI, 2011, pp. 154-155).

Embora se pretenda facilitar a resolução de conflitos de modo administrativo, é indubitável que, pelo princípio da legalidade e para que não haja ofensas ao princípio da impessoalidade, não se pode permitir que as negociações de uma transação administrativa fiquem completamente postas ao entendimento discricionário da Administração. Por outro lado, a transação administrativa não seria adequadamente viabilizada caso venha a repetir a mesma estruturação da transação tributária e ser condicionada em uma esfera mais abstrata, ou seja, por lei que trataria das condições da negociação em si. Ou seja: há de se encontrar um ponto de equilíbrio entre a total discricionariedade e a completa dependência de lei autorizativa.

Para suprir a situação, parece coerente a proposta de elaboração de uma lei geral de transação que não condicione desde logo as tratativas, mas que deixe para a discricionariedade administrativa a negociação sobre o que se vai transacionar. Nesse sentido, "pode a Administração Fiscal, devidamente autorizada por lei, como prevê o anteprojeto de lei de transação, manejar poderes-deveres discricionários que a habilitem celebrar, consensualmente, transação administrativo-tributária” (SARAIVA e GUIMARÃES, 2008, p. 40). 
O anteprojeto a que se refere o exercto acima é o encaminhado pela Procuradoria Geral da Fazenda Nacional em 2007, veiculado por meio do ofício n 624/PGFN-PG, que trata de transação administrativa-tributária. Mas sofreu críticas por atacar fortemente o princípio da impessoalidade (FERNANDES, 2015, p. 135). Entretanto, caso ajustado e mais bem justificado, uma nova proposta pode ser apresentada. Nesse caso, seria interessante propor uma lei geral da transação administrativa, e não apenas de assuntos tributários.

Isso porque permitir a transação com base nos critérios vistos no caso concreto pela Administração Pública não fere o princípio da legalidade. A transação administrativa seria autorizada por uma lei geral, que traria um rol de deveres e responsabilidades para o servidor encarregado de transacionar. Ao mesmo tempo, poderia indicar limites de valores e de situações possíveis de transação.

De início, a transação administrativa poderia, inclusive, ser adotada apenas por certos órgãos que tem um percentual maior de litigância e em que se observasse que a transação seria utilizada de pronto como um mecanismo efetivo de busca do interesse público. Na lei geral da transação administrativa, deveria haver previsão para que o gestor justifique o uso da transação como mais oportuna para o interesse público do que a inação, ou seja, deveria ser motivado o uso do instrumento transacional.

Ademais, também deveria ser prevista expressamente que a lei transfere aos administradores a responsabilidade subjetiva por constatação das condições da negociação e estabelecimento do acordo. Assim, uma vez demonstrada a intenção do servidor em autorizar concessões mútuas em que a parte concedida pela Administração não se demonstrasse razoável perante as condições do fato e da lei geral da transação administrativa, o agente poderia ser responsabilizado. Sem desconsiderar, por óbvio, que o particular de má-fé também poderia ser alcançado por eventuais punições caso demonstrada sua participação no desacerto.

Nos Estados Unidos, por exemplo, existem previsões para a delegação a autoridades administrativas para que estas analisem o caso concreto e estabeleçam as condições que entender cabíveis para o sucesso da transação:

Code Sec. 71211 authorizes the Secretary of the Treasury to enter into closing agreements with any person relating to that person's tax liability in respect of any internal revenue tax for any taxable period. By order, the Treasury Secretary has transferred all of his authority to enter into closing agreements to the Commissioner 
of Internal Revenue. The Commissioner's authority to enter into closing agreements is further delineated in Reg. \$301.7121-1(a): "The Commissioner may enter into a written agreement with any person relating to the liability of such person ... in respect of any internal revenue tax for any taxable period ending prior or subsequent to the date of such agreement." (GAWLIK e NAPKA, 2009, p. 29).

Ademais, cabe esclarecer que "os interesses da Fazenda Pública, por representarem o que a doutrina denominou de interesses públicos secundários, podem ser sim, nos estritos limites legais, objeto de transação tributária, prevista em dispositivos do CTN (art. 156, III, e art. 171)" (SARAIVA e GUIMARÃES, 2008, p. 31).

Como exemplo em que a aplicação da transação administrativa pode ser admitida, aborda-se que, em questões que ainda não se destinaram à seara judicial, quando o particular ainda está pleiteando administrativamente, a transação poderia ser admitida desde que objetivamente já se esteja diante de uma situação em que há reconhecimento da procedência do pedido do requerente.

Deve-se perceber que o destrave das possibilidades negociais, por meio da transação administrativa, da Administração Pública tende a gerar aumento de receita imediata e giro financeiro para a economia. Em situações de débitos tributários volumosos - ou até de medianos ou pequenos - o Poder Público pode perceber que é melhor negociar com o particular diretamente e aceitar e ceder sob determinadas condições para que tenha o pagamento devido em vez de esperar imbróglios judiciais a se arrastarem no tempo. Isso sob o risco de dilapidação de um patrimônio que estava ali se oferecendo para ser resgatado. Quanto ao contribuinte, ele pode se organizar melhor financeiramente, com mais dados concretos para o planejamento tributário e, consequentemente, para seus eventuais negócios ${ }^{8}$. Disso decorre, por exemplo, que o devedor de um tipo específico de tributo, estendendo a duração da sua existência por meio de um instrumento de transação, pode, no futuro, gerar ainda mais tributos a serem arrecadados pelo fisco. O que não ocorreria se a estabilização do conflito entre contribuinte e Estado demorasse a ocorrer e com o risco de ainda gerar consequências danosas à continuidade das atividades do contribuinte, mas que não eram assim vistas de antemão.

\footnotetext{
${ }^{8}$ Terry indica que as transações - closing agreements - "protect the federal government from losses of revenue and the taxpayer from further assessments" (TERRY, op. cit., p. 428).
} 
Mas, repete-se, não só em casos tributários a transação administrativa poderia ser utilizada. Sabe-se que, por vezes, a Administração Pública prefere não agir e não consertar eventual erro de imediato, por correr o risco de maltratar o interesse público que a órbita por todos os lados, como um Big Brother orwelliano, embora reconheça a prática daquele erro. Entretanto, ainda acaba por ser responsabilizada posteriormente, quando já poderia ter atuado para encontrar a solução administrativa, mesmo que fosse para beneficiar o particular, tendo em vista que eventual ilegalidade perante o particular não deixa de ser ilegalidade também perante a Administração Pública.

Tratando dessa questão, ao abordar o excessivo apego ao formalismo, Machado Segundo e Raquel Machado (2014, p. 1258) advertem que “em desfavor da Administração, não há nada que o impeça, até porque é ela própria quem está agindo, sendo de seu interesse, pelo menos em tese, a correção de qualquer ilegalidade, ainda que para favorecer o cidadão que com ela se relaciona".

A omissão de decidir, por exemplo, em uma Autarquia estadual gera eventual ação perante a Justiça do Estado sede da Autarquia (movimentação da máquina judiciária: oficiais, correio, energia, servidores), o que tem como consequência mais gastos para o erário público, cujos recursos se encontram em uma conta única por determinação legal.

Dessa forma, a autorização para negociar com os particulares, via transação administrativa, simplificaria o pagamento de indenização antes do ingresso do particular na Justiça. Como sugestão para o adequado funcionamento do instrumento proposto para a solução de litígios, infere-se que o caso transacionado deve estar previsto na lei geral de transação e ser de entendimento comum que aquele erro causado pela Administração foi realmente ela quem causou e que é devida reparação. Por que esperar o acontecimento da inescapável lide judicial? O juiz também não seria parte do Estado? Não seria o Estado a decidir em última instância mesmo em caso de demandas administrativas levadas a questionamentos judiciais?

Embora se tenha consciência da essencialidade da separação dos poderes, não é apenas ao Judiciário que cabe obrigar o Executivo a dispor de seus bens em ações de responsabilidade quando reconhece o erro estatal. O Executivo, ou outro Poder no uso de funções administrativas, pode se resguardar do pagamento de maiores valores e de honorários advocatícios caso anteveja soluções pactuadas com o particular para dirimir os prejuízos. 
Haveria ofensa ao interesse público nesta antecipação da solução? Pensa-se que não. Pensa-se que, em último grau, o Judiciário também atacaria o interesse público caso condene o Poder Público. No entanto, isso seria contraditório.

Dentre os benefícios indiretos da transação administrativa, destaca-se, portanto, a diminuição das demandas judiciais ${ }^{9}$ contra a Fazenda Pública, o que, por consequência, poderia ser dividido em duas especificidades. Primeiro, o gasto com o pagamento de condenações diminuiria, uma vez que já seria pago, a menor e administrativamente, o valor devido na eventual sentença condenatória.

A segunda especificidade está relacionada à quantidade de processos envolvendo a Administração Pública, o que influi no tamanho do Judiciário e também na intromissão do Judiciário em assuntos administrativos quando seria mais aconselhável que o Judiciário não agisse de modo algum nas demandas de responsabilidade primária do Executivo. Nesta situação, o Judiciário, uma vez que julgaria menos ações envolvendo o Poder Público, também teria menos oportunidade de se imiscuir, por exemplo, em certas políticas públicas. Quanto àquela situação, do tamanho do Judiciário, com menos ações, ele seria menos utilizado, o que, indo ao encontro do interesse público, diminuiria certamente o montante de despesas com seu funcionamento.

Ademais, tomando o lado do contribuinte, se quisermos superar o estigma de que o cidadão está sempre pronto a burlar o pagamento e que, portanto, eventual negociação com o contribuinte serviria para abafar ou formalizar eventual desvio, devemos tratar o devedor com a presunção que ele está de boa-fé. O que pressupõe também deixar de tratar a Fazenda Pública como parte débil na relação tributária ${ }^{10}$.

A vulnerabilidade poderia ser argumentada, inclusive, de modo mais favorável ao contribuinte, tendo em vista que:

O Estado fiscal é o único credor nos quadrantes do Direito que é simultaneamente, per se, criador, executor e julgador da relação obrigacional e - $\log$ o - o contribuinte é o único devedor no ordenamento jurídico cujo credor exerce tríplice função na relação obrigacional (MARINS DE SOUZA, 2009, p. 24).

\footnotetext{
${ }^{9}$ TERRY (1973, p. 428): “This closing agreement constitutes an effective method of settling or avoiding disputes that could result in litigation”.

${ }^{10}$ Marins de Souza (2009, p. 14) protesta no sentido de que "o axioma da debilidade fazendária é paradoxal diante dos fatos e paradoxal diante do vetor axiológico constitucional e - $\log$ - é falso".
} 
Portanto, a Administração Pública, como parte forte da relação perante os cidadãos, tem condições de, antevendo que a solução administrativa trará mais benefícios às consecuções do interesse público, poder fazer uso da transação administrativa. Ao mesmo tempo, o cidadão, desde que respeitada a manifestação de sua vontade, terá meios de ter suas contendas resolvidas com mais celeridade e, consequentemente, poder ter mais previsibilidade de como agir e mais segurança jurídica quanto a seus direitos ou deveres questionados administrativamente.

Como complemento, destaca-se que a transação administrativa deve ser acompanhada de perto pela Administração Público, mormente por órgãos de fiscalização, e que se considere efetivamente aperfeiçoada apenas quando se puder constatar o cumprimento do acordado perante as partes. Como forma de analogia, que se tome a transação administrativa como um modelo de suspensão do conflito até que seja aferida a completa execução do combinado perante as partes envolvidas. Ou seja, em comparação com instrumentos intrinsecamente tributários, a transação administrativa mais se assemelharia a uma suspensão de exigibilidade do que a uma extinção.

Deve-se atentar, do mesmo modo, para que se transacione com a autoridade a que a lei geral deu competência para que tratasse das condições específicas da transação no caso concreto, sob risco de não se poder exigir o cumprimento das obrigações do Poder Público ${ }^{11}$.

\section{CONSIDERAÇÕES FINAIS}

A Administração Pública deve cessar de se esconder sob as confortáveis cobertas da argumentação da supremacia e intangibilidade do interesse público e retirar-se da inércia em situações nas quais pode intervir para a solução efetiva e célere de conflitos perante os administrados. Deve-se adotar outra postura quanto às alegações de falta de atuação da Administração Pública por causa da indisponibilidade do interesse público, ao mesmo tempo

\footnotetext{
${ }^{11}$ Nesse sentido, Gawlik e Napka, (2009, p. 35) retratam que: "In the end, closing agreements executed by individuals without authority to bind the parties will not be enforced".
} 
em que se percebe que o interesse público pode sim ser prejudicado ainda que esse argumento seja utilizado em sua defesa.

Dessa forma, neste trabalho, procurou-se demonstrar que o Poder Público tem possibilidade de atuar de modo mais ativo para solucionar litígios administrativos, o que ocorreria por meio da transação administrativa. Por esse instrumento, portanto, que seria autorizado por uma lei geral, ao administrador seria delegado o poder de negociação das condições em que se poderia transacionar.

Ademais, percebeu-se que a transação administrativa seria ferramenta que atende ao interesse público na medida em que daria solução de efetividade a problemas que tardariam a ser resolvidos e que poderiam trazer prejuízo à sociedade, como por exemplo, a demora na entrada de recursos via pagamento de créditos tributários discutidos na Justiça por anos que já poderiam estar ao serviço do interesse público se tivesse ocorrido o pagamento por meio de transação com condições estabelecidas pelo Poder Público diretamente. Tal situação evitaria a configuração de uma situação prejudicialmente estática sobre a resolução dos conflitos administrativos, dispensando-se a necessidade de uma lei autorizativa a apresentar as eventuais condições para a negociação, e diminuindo a utilização de eventuais demandas judiciais.

\section{REFERÊNCIAS}

BINENBOJM, Gustavo. Da supremacia do interesse público ao dever de proporcionalidade: um novo paradigma para o direito administrativo. Revista de Direito Administrativo, Rio de Janeiro, v. 239, p. 1-32, jan. 2005. Disponível em: <http://bibliotecadigital.fgv.br/ojs/index.php/rda/article/view/43855/44713>. Acesso em: 22 Jun. 2018.

BOAROLI, Caroline Melo; Peixoto, Maurício Muriack de Fernandes e. A Transação Como Forma de Extinção do Crédito Tributário: Uma Análise das Alterações Preconizadas Pelos Projetos de Lei No 5.082/2009 e 469/2009, Sob a Égide dos Princípios da Administração Tributária. Revista Opinião Jurídica, Fortaleza, ano 9, n. 13, p.217-255, jan./dez., 2011. Disponível em: $<$ http://periodicos.unichristus.edu.br/index.php/opiniaojuridica/article/view/790/250>. Acesso em 21 jun. 2018. 
COSKUN, Denz. Religious Skepticism, Cambridge Platonism, and Disestablishment. University of Detroit Mercy Law Review, vol. 83, n. 5, 2006, p. 579-600.

FERNANDES, Rayneider Brunelli Oliveira. A Transação Tributária a Serviço da Consensualidade e da Eficiência Administrativa. Revista da Faculdade de Direito da UERJ-RFD, n. 27, 2015, p. 121-145.

GABARDO, Emerson. O principio da supremacia do interesse público sobre o interesse privado como fundamento do Direito Administrativo Social. Revista de Investigações Constitucionais, vol. 4, n. 2, 2017, p. 95-130.

GAWLIK, Gregory J.; NAPKA, LaVonda D. Authority - Authority - Of Course I Have Authority - Thoughts on Closing Agreements, Delegation Orders and Signature

Authority. Journal of Tax Practice and Procedure, v. 11, n. 3, Junho-Julho, 2009, p. 29-36.

HOLMES, Stephen; SUNSTEIN, Cass R. The Cost of Rights: Why Liberty Depends on Taxes. W.W. Norton \& Company. New York, 1999, 255 p.

HOULE, France; MOCKLE, Daniel. Conciliation des Litiges et Formes Alternatives de Regulation en Droit Administratif Federal. Osgoode Hall Law Journal, v. 36, n. 4, 1998, p. 703-770.

KIRCHHOF, Paul. Tributação no Estado Constitucional. Tradução de Paulo Adamy. São Paulo: Quartier Latin, 2016, p. 11-24.

LOPES FILHO, Juraci Mourão. Participação de OS e OSCIP em Certame Licitatório. Revista Opinião Jurídica, v. 4, n. 8, 2006. Disponível em: <http://periodicos.unichristus.edu.br/index.php/opiniaojuridica/article/view/2028/616>. Acesso em: 22 jun. 2018.

LEWIS, Carol W. In Pursuit of the Public Interest. Public Administration Review, v. 66, n. 5, 2006, p. 694-701. Disponível em: 〈www.jstor.org/stable/3843898.>. Acesso em: 21 jun. 2018

MACHADO SEGUNDO, Hugo de Brito; MACHADO, Raquel Cavalcanti Ramos. Prova e Verdade em Questões Tributárias. Revista do Instituto do Direito Brasileiro, v. 2, p. 12451280, 2014. 
MARINS DE SOUZA, James J.. Defesa e vulnerabilidade do contribuinte. São Paulo: Dialética, 2009. 223 p.

SARAIVA FILHO, Oswaldo Othon de Pontes; GUIMARÃES, Vasco Branco (org.).

Transação e arbitragem no âmbito tributário: homenagem ao jurista Carlos Mário da Silva Velloso. Belo Horizonte: Forum, 2008.

SCHIEFLER, Gustavo Henrique Carvalho. A Possibilidade de Negociação em Caso de Descumprimento do Contrato Administrativo e a Questão da Indisponibilidade do Interesse Público. Artigo eletrônico, 2016. Disponível em: <http://bit.do/enLWq>. Acesso em: 22 jun. 2018.

SCHIER, Paulo Ricardo. Ensaio sobre a supremacia do interesse público sobre o privado e o regime jurídico dos direitos fundamentais. Revista Pensar, v. 2, n. 2, 2007. Disponível em: 〈http://periodicos.unifor.br/rpen/article/view/850/1686>. Acesso em 22 jun. 2018.

SIMARD, Caroline J. Modulation de l'Interet Public et du Service Public Selon le Nouveau Regime Concurrentiel International: Le Cas des Services de l'Information et des Communications, La. Revue quebecoise de droit international vol. 18, n. 1, 2005, p. 141-170.

TERRY, Robert J. The Scope of Closing Agreements. American Bar Association Journal, v. 59, n. 4, Abril 1973, p. 428-430.

VOLPI, Elon Kaleb Ribas. Conciliação na Justiça Federal. A indisponibilidade do Interesse Público e a Questão da Isonomia. Revista da PGFN. 2011, p. 139-164. Disponível em: <http://www.pgfn.fazenda.gov.br/centrais-de-conteudos/publicacoes/revista-pgfn/ano-inumero-ii-2011/012.pdf>. Acesso: 20 jun. 2018. 